\title{
Between spiritual wellbeing and spiritual distress: possible related factors in elderly patients with cancer
}

\author{
Sílvia Caldeira ${ }^{1}$ \\ Emilia Campos de Carvalho² \\ Margarida Vieira ${ }^{3}$
}

Objective: this article describes the assessment of the spiritual wellbeing of elderly patients with cancer submitted to chemotherapy and possible predictive factors of the spiritual distress diagnosis. Methodology: this is a methodological study for clinical validation of a nursing diagnosis, using interviews to assist in completing the form. Results: 45 elderly patients participated in this study, Catholics, mostly female, diagnosed with breast cancer, average age of 70.3 years. The prevalence of spiritual distress was of $42 \% ; 24.4 \%$ of the elderly patients were under anti-depressant medication. A significant association was noted between spiritual distress, antidepressant medication and level of education; an increase (not significant) was acknowledged at the start of the treatment. Conclusion: these results emphasize the relevance of clarifying this diagnosis and the responsibility of nurses to provide spiritual care to patients. Interventions should be planned appropriately every time a nursing diagnosis is identified as a complex answer and for which pharmacological treatment is not sufficient.

Descriptors: Nursing; Spirituality; Nursing Diagnosis; Aged; Neoplasms.

\footnotetext{
${ }^{1}$ PhD, Assistant Professor, Instituto de Ciências da Saúde, Universidade Católica Portuguesa, Lisboa, Portugal.

${ }^{2}$ PhD, Full Professor, Escola de Enfermagem de Ribeirão Preto, Universidade de São Paulo, WHO Collaborating Centre for Nursing Research Development, Ribeirão Preto, SP, Brazil.

${ }^{3} \mathrm{PhD}$, Associate Professor, Instituto de Ciências da Saúde, Universidade Católica Portuguesa, Porto, Portugal.
}

Corresponding Author:

Sílvia Maria Alves Caldeira Berenguer

Universidade Católica Portuguesa. Instituto de Ciências da Saúde CEP: 1500-467, Lisboa, Portugal

E-mail: caldeira.silvia@gmail.com
Copyright @ 2014 Revista Latino-Americana de Enfermagem This is an Open Access article distributed under the terms of the Creative Commons Attribution Non-Commercial License (CC BY-NC).

This license lets others distribute, remix, tweak, and build upon your work non-commercially, and although their new works must also acknowledge you and be non-commercial, they don't have to license their derivative works on the same terms. 


\section{Introduction}

In the context of health care, holistic support to patients is increasingly desirable, which will translate in the duty of nurses to assist to the entire patient's needs, whether they are related to the biopsychosocial dimension or needs of spiritual nature. The inclusion and importance of spirituality in nursing have been emphasized by its relevance in the quality of care and in the patient's wellbeing, in particular in the elderly patients, cancer patients and end of life patients ${ }^{(1-4)}$. The word spirituality comes from the expression spiritus, which means breath of life. It is related with higher questions in life, as it permits to query, seek and find the meaning of its life ${ }^{(5-6)}$. Every person will have different ways of finding the meaning of life, giving spirituality an individual, dynamic and subjective character. Further to the meaning of life, spirituality is intimately related to beliefs, values and transcendence ${ }^{(7)}$. Hence, every person is a spiritual being and nurses should attend to those needs of religious patients and of those who consider themselves atheists or agnostics. The more critical situations in life that convey the possibility of death, confronting the person with its end, are the ones swathed in spiritual nature ${ }^{(8)}$. Illness is an example of one of these situations and nurses are health professionals present in this period and who have the opportunity to diagnose, act and promote positive results subject to their interventions. Equally, elderly patients, as they approach the end of life, will adopt a more regular religious or spiritual practice, resuming the comfort of faith or a way of life that will permit finding meaning and peace ${ }^{(3,9)}$. Cancer is a feared illness, as it is linked to a premature arrival of death and also to the suffering caused by the associated treatments. The prevalence is higher in this age group.

NANDA-I defines the spiritual distress diagnosis as "the impaired ability to experience and integrate meaning and purpose in life through connectedness with self, others, art, music, literature, nature, and/ or a power greater than oneself"(10). This diagnosis is included in NANDA-I since 1978; however, the validation studies did not consider the patients' opinion, only the opinion of the experts, through the content validation model of Richard Fehring. Its clinical validation is necessary, using an approach to patients in order to develop a standardized language related to spirituality ${ }^{(11)}$. Diagnostic validation studies add to the accuracy and facilitate identification by nurses in their clinical practice(12).
The subjectivity of the spirituality concept and the lack of preparation of nurses are two factors that substantiate the insufficient inclusion of spiritual interventions in healthcare practice ${ }^{(5,13-14)}$. Spiritual care includes the assessment of spiritual wellbeing, the formalization of diagnoses of spiritual nature that precede the definition of interventions and evaluation of results, thus completing the scientific work method used by nurses, which is the nursing process.

The identification of the nursing diagnosis spiritual distress in elderly patients submitted to chemotherapy treatment enables nurses to deliver holistic care, which includes autonomous and interdependent interventions according to the specific needs of every patient, promoting spiritual wellbeing; this is, finding the meaning of life through the connexion with self and with others, with the world and with a greater being.

In this article, we aim to describe the assessment of spiritual wellbeing in elderly patients with cancer submitted to chemotherapy and to identify possible factors that relate to spiritual distress.

\section{Methods}

A validation study of the spiritual distress diagnosis (00066) from NANDA-I was carried out, using the model of clinical validation of Richard Fehring(15). This study was preceded by two methodological stages: one was the integrative literature review and the other the validation with experts. During the clinical validation phase, as the diagnosis to be validated, we opted to hold interviews with patients and fill out a five-part form: the first part contained the identification details; the second part the clinical indicators of spiritual distress with its operational definition; the third part the diagnose of presence or absence of spiritual distress reached by the researcher; the spiritual wellbeing questionnaire was the fourth part, whose score was considered as one of the criteria to identify the diagnosis. Finally, the fifth part included a question that enabled the patient to confirm or deny having spiritual distress.

The spiritual wellbeing questionnaire (SWBQ) is an instrument that permits the assessment of spiritual wellbeing through five levels of reply in 20 statements, divided into four dimensions: personal, community, environmental and transcendental (16). The questionnaire was previously validated for use in Portuguese ${ }^{(17)}$.

It was defined that the concurrence of the three following criteria would be determinant to identify a patient in spiritual distress: diagnosis by researcher, 
score in the spiritual wellbeing questionnaire equal to or less than 3, and patient confirmation of spiritual distress.

The sample was selected from a larger study that included 170 patients over 18 years old, oriented and in circumstances that allowed participation, submitted to intravenous or oral chemotherapy, attending the selected centre to develop this research. For this article, we considered 45 patients with age over 65 years old.

In respect of ethical principles and patient's vulnerability on their first chemotherapy session or patients who had a close relationship with the researcher were excluded during the collection of data. The study was authorized by the hospital, with a positive review from the ethics commission (S.1116122/5 de 11/11/2011). Anonymity and data confidentiality were guaranteed to patients, information and an environment with privacy was ensured during participation in this study. Also, for patients who during the interview evidenced needs that would require intervention, consent was obtained to share the appropriate information with the healthcare team in order to achieve an effective action.
The statistical analysis was performed using SPSS program, version 17.0.

\section{Results}

A sample of 45 elderly patients was obtained, with ages comprised between 65 and 83 years old, with an average of 70.3 years old. The sample consisted in its majority of females $(\mathrm{N}=27,60 \%)$, civil status married $(n=31,68.9 \%)$. All the participants were Catholics. The majority ( $\mathrm{N}=42,93.3 \%$ ) was submitted to intravenous chemotherapy, did not have metastasis $(\mathrm{N}=39,86.7 \%)$, did not have any dependants either financially, for education or for care $(\mathrm{N}=33,73.3 \%)$. A vast number of the elderly were escorted to hospital for the treatment sessions by a significant person or a family member $(\mathrm{N}=32,71.1 \%)$. The most frequent type of cancer found in women was breast cancer and in men bowel cancer.

Considering the defined criteria to identify patients diagnosed with spiritual distress, a prevalence of $42.2 \%$ was obtained (Table 1).

Table 1 - Criteria for identification of spiritual distress and prevalence of diagnosis

\begin{tabular}{|c|c|c|c|c|c|c|}
\hline & \multicolumn{2}{|c|}{ Yes } & \multicolumn{2}{|c|}{ No } & \multicolumn{2}{|c|}{ Total } \\
\hline & $\mathbf{n}$ & $\%$ & $\mathrm{n}$ & $\%$ & $\mathbf{N}$ & $\%$ \\
\hline Patient(a) & 20 & 44.4 & 25 & 55.6 & 45 & 100.0 \\
\hline Researcher(b) & 21 & 46.7 & 24 & 53.3 & 45 & 100.0 \\
\hline Spiritual Distress $\left(a^{*} b^{*}\right.$ SWBQ) & 19 & 42.2 & 26 & 57.8 & 45 & 100.0 \\
\hline
\end{tabular}

The average duration of the interview was 41.5 minutes, against 48.3 minutes among the elderly with spiritual distress and 36.6 minutes among the elderly with no spiritual distress. With $p$-values inferior to 0.05 , we infer that the presence of spiritual distress influences the duration of the interview, increasing its length (Table 2).

Table 2 - Comparison between the length of the interview in patients with spiritual distress and patients with no spiritual distress

\begin{tabular}{lccccc}
\hline & \multicolumn{2}{c}{ Length of interview (min) } & & \multicolumn{2}{c}{ t-Student } \\
\cline { 5 - 6 } \cline { 5 - 6 } & Average & Min-Max & & t & \multicolumn{1}{c}{} \\
\hline Patient in spiritual distress & & & & -4.171 & 0.000 \\
No & 36.6 & $22-55$ & & \\
Yes & 48.3 & $35-75$ & & \\
Total & 41.5 & $22-75$ & & \\
\hline
\end{tabular}

We tried to establish associations between the characterization variables of the patients and the presence of spiritual distress and, through a model of logistic regression, the variables "Taking antidepressants" and "Level of education" were found to have a significant effect on the presence of spiritual distress. However, the adjustment of this model exposed its weaknesses; consequently, the variable analysis was undertaken in pairs (Table 3 ). Regarding the administration of chemotherapy, all of the 19 elderly patients in spiritual distress have medication prescribed intravenously. The fact of taking anti-depressants was associated to the presence/absence of spiritual distress, since the obtained proof value was 0.033 , which is inferior 
to 0.05 . Thus, we rejected the hypothesis of these being independent variables. Concerning the elderly patients in spiritual distress, $42.1 \%$ take anti-depressants, against $11.5 \%$ for the elderly patients with no spiritual distress. These results permit estimating the increase of risk for spiritual distress between 1.23 and 4.12 in patients taking anti-depressants $(O R=2.248)$. Spiritual distress was found in $42.2 \%$ of the elderly patients, however, when assessing the probability determined by the fact of not taking anti-depressants, the percentage decreases to $32.4 \%$ and, among the elderly patients taking antidepressants, the percentage increases to
$72.7 \%$. Although we did not apply any assessment tool regarding depression, we are aware that this medication can be used for different therapeutic purposes. Hence, we only considered the information regarding being medicated with anti-depressants as a characterization variable of the study participants.

In the elderly patients with primary education or university level education, the spiritual distress diagnosis was more commonly found, as the proof value observed in the test was 0.043 . The elderly patients in spiritual distress have incomplete primary education, which was also the most frequent education level in this sample.

Table 3 - Characterization of the elderly patients according to presence/absence of spiritual distress

\begin{tabular}{|c|c|c|c|c|c|c|c|c|}
\hline & \multicolumn{6}{|c|}{$\begin{array}{c}\text { Spiritual distress } \\
\text { (Researcher*Patient* SWBQ) }\end{array}$} & \multicolumn{2}{|c|}{$\begin{array}{c}\text { Independence } \\
\text { test }\end{array}$} \\
\hline & \multicolumn{2}{|c|}{ No } & \multicolumn{2}{|c|}{ Yes } & \multicolumn{2}{|c|}{ Total } & \multirow{2}{*}{$(\mathrm{X})$} & \multirow{2}{*}{$p$} \\
\hline & $\mathbf{n}$ & $\%$ & $\mathbf{n}$ & $\%$ & $\mathbf{N}$ & $\%$ & & \\
\hline Chemotherapy & & & & & & & 2.349 & 0.309 \\
\hline IV & 23 & 88.5 & 19 & 100.0 & 42 & 93.3 & & \\
\hline Oral & 1 & 3.8 & 0 & 0.0 & 1 & 2.2 & & \\
\hline Both & 2 & 7.7 & 0 & 0.0 & 2 & 4.4 & & \\
\hline Metastasis & & & & & & & 0.172 & 0.679 \\
\hline No & 23 & 88.5 & 16 & 84.2 & 39 & 86.7 & & \\
\hline Yes & 3 & 11.5 & 3 & 15.8 & 6 & 13.3 & & \\
\hline Anti-depressants & & & & & & & 5.554 & $0.033^{*}$ \\
\hline Yes & 3 & 11.5 & 8 & 42.1 & 11 & 24.4 & & \\
\hline No & 23 & 88.5 & 11 & 57.9 & 34 & 75.6 & & \\
\hline Escorted to treatment & & & & & & & 0.116 & 0.734 \\
\hline Yes & 19 & 73.1 & 13 & 68.4 & 32 & 71.1 & & \\
\hline No & 7 & 26.9 & 6 & 31.6 & 13 & 28.9 & & \\
\hline Gender & & & & & & & 0.137 & 0.712 \\
\hline Male & 11 & 42.3 & 7 & 36.8 & 18 & 40.0 & & \\
\hline Female & 15 & 57.7 & 12 & 63.2 & 27 & 60.0 & & \\
\hline Civil status & & & & & & & 1.972 & 0.373 \\
\hline Single & 2 & 7.7 & 2 & 10.5 & 4 & 8.9 & & \\
\hline Married & 20 & 76.9 & 11 & 57.9 & 31 & 68.9 & & \\
\hline Widowed & 4 & 15.4 & 6 & 31.6 & 10 & 22.2 & & \\
\hline Level of education & & & & & & & 4.111 & $0.043^{*}$ \\
\hline University & 5 & 19.2 & 0 & 0.0 & 5 & 11.1 & & \\
\hline Basic & 21 & 80.8 & 19 & 100.0 & 40 & 88.9 & & \\
\hline Do you have any dependants? & & & & & & & 0.530 & 0.467 \\
\hline Yes & 8 & 30.8 & 4 & 21.1 & 12 & 26.7 & & \\
\hline No & 18 & 69.2 & 15 & 78.9 & 33 & 73.3 & & \\
\hline How important has religion/spirituality been in your life? & & & & & & & 2.180 & 0.336 \\
\hline Little & 2 & 7.7 & 0 & 0.0 & 2 & 4.4 & & \\
\hline Relevant & 5 & 19.2 & 6 & 31.6 & 11 & 24.4 & & \\
\hline Very Relevant & 19 & 73.1 & 13 & 68.4 & 32 & 71.1 & & \\
\hline $\begin{array}{l}\text { Did the importance of religion/spirituality change } \\
\text { after illness? }\end{array}$ & & & & & & & 0.900 & 0.638 \\
\hline More relevant & 13 & 50.0 & 11 & 57.9 & 24 & 53.3 & & \\
\hline Less relevant & 1 & 3.8 & 0 & 0.0 & 1 & 2.2 & & \\
\hline No & 12 & 46.2 & 8 & 42.1 & 20 & 44.4 & & \\
\hline Total & 26 & 100.0 & 19 & 100.0 & 45 & 100.0 & & \\
\hline
\end{tabular}

* Fisher's exact test 
In this sample, the proof values were superior to 0.05 . Therefore, there is no statistical evidence to state that the time of diagnosis or the time of the first treatment, or also the time of the current treatment, presented significant differences between elderly patients with spiritual distress and elderly patients without that diagnosis. However, in table 4, it cannot be verified that the elderly patients in spiritual distress were the ones who found out they had cancer more recently (18.2 months), the ones who had the first chemotherapy session more recently ( 9.5 months) and the ones submitted to chemotherapy treatments for less time (5.9 months).

Table 4 - Comparison between times of treatment and diagnosis among elderly patients with spiritual distress and no spiritual distress

\begin{tabular}{|c|c|c|c|c|c|}
\hline \multirow{2}{*}{ Time in months } & \multicolumn{3}{|c|}{ Spiritual distress } & \multicolumn{2}{|c|}{ Mann-Whitney } \\
\hline & No & Yes & Total & $\mathrm{U}$ & $p$ \\
\hline Diagnosis & 38.8 & 18.2 & 30.1 & 178.5 & 0.115 \\
\hline 1st treatment & 13.7 & 9.5 & 11.9 & 208.5 & 0.375 \\
\hline Actual time of treatment & 7.1 & 5.9 & 6.6 & 234.5 & 0.773 \\
\hline
\end{tabular}

\section{Discussion}

The data permitted the identification of patients in spiritual distress, similarly to another clinical validation study for this diagnosis among patients with renal failure $^{(18)}$. The prevalence of the diagnosis adds scientific evidence to this area of the nursing discipline considered more subjective. This finding reflects the necessity to find strategies to ease not only the identification of spiritual distress, but also the knowledge necessary to plan appropriate interventions. One of those strategies, regularly indicated in scientific publications, is the education of nursing students and the inclusion of spirituality in the nursing curricula(19-20). Although the holistic conception in the approach to patients is present in the curricula, the contents related to spirituality are insufficient when compared to other contents necessary to provide care and to enable the acquisition of the necessary competencies for spiritual care(21). However, other questions have been involved in this discussion, based on ethical arguments related with the duty of providing spiritual care or with the incompatibility of values and beliefs between nurses and patients. Other pedagogical arguments are related with teaching spiritual care and the necessary conditions for it to be effective, such as the preparation of teachers and the timing during the education process. These questions are essential to the nursing discipline when considering the human response spiritual distress.

The interviews of patients diagnosed with spiritual distress were longer. The competencies related with the interpersonal relationship and communication are considered as central in spiritual care ${ }^{(21)}$. The patients in spiritual distress are suffering, so sharing and active listening by nurses are desirable and therapeutic interventions. Most times, the unbalanced nurse/patient ratio does not allow this personalized attention and the professional prioritizes other aspects of care that do not require as much availability to be with the patient. Although this was not the main purpose of the research, it was noted that, after the interviews the patients confirmed the therapeutic nature of the interview, and expressed their gratitude for being heard and able to share their feelings. The assessment of spirituality and identification of patients in spiritual distress could help nurse managers to plan the workload of the team, with time as a useful resource in the delivery of care.

The majority of patients in spiritual distress were medicated with antidepressants. The diagnosis of depression was not confirmed, but it was only considered that the patient was medicated with antidepressants. Some indicators of spiritual distress are similar to the signs and symptoms of depression; however, depression is a deeply profound experience, as it affects the person in all of its being and existence ${ }^{(22)}$. Albeit, the similarity between some of the defining characteristics of spiritual distress and signs and symptoms of depression have both been defined in distinct situations(23-25).

Signs and symptoms of depression are more related with the personal dimension of spiritual wellbeing, awarding to depression an alteration of the emotional status, which in a holistic perspective is always experienced by the person as a whole. The defining characteristics of spiritual distress are more specific and related with the spiritual experience, whilst the signs of depression are more generic ${ }^{(23-25)}$. The recurrent thought of death and attempt of suicide are common in depression but were not identified in the interviews with these patients, to whom chemotherapy represented an opportunity to improve their health condition, to achieve 
greater wellbeing or even a cure. However, the wish of a quick death was identified in patients with terminal cancer, when they presented depression, hopelessness and a decrease in spiritual wellbeing(25). The interventions of nurses facing a patient in spiritual distress and a patient with a medical diagnosis of depressions are different. Therefore, nurses should be capacitated to assess and diagnose spirituality related phenomena and, thus, to include spiritual interventions in their clinical practice and sustain gains in health related to this intervention.

Although with no significant statistical evidence, the time of illness and treatment is a fact that should alert nurses during spiritual wellbeing assessment, since spiritual distress was diagnosed in patients with less time since the diagnosis and treatment.

\section{Conclusion}

The assessment of spiritual wellbeing in elderly patients with cancer should be included in the comprehensive assessment performed by nurses, as spiritual distress was identified as a nursing diagnosis in $42 \%$ of this sample. This prevalence appeals for nurses to be prepared to attend to these patients by integrating these features in the curricula and for nurse managers to organize resources to enable nurses to intervene efficiently. One of the resources could be the time to be with and listen to the patients. Although medicated with antidepressants, patients could be in spiritual distress and this suffering should not be presumed as resolved by the pharmacological intervention; demanding comprehensive attention from nurses, in particular to patients for whom diagnosis and treatment were more recent. The statistical evidence collected in this study in an area considered as subjective accrues to the scientific evidence required to include spirituality in the delivery of nursing care.

\section{References}

1. Monod S, Rochat E, Bula C, Jobin G, Martin E, Spencer

B. The spiritual distress assessment tool: an instrument to access spiritual distress in hospitalized elderly persons". BMC Geriatrics. [Internet]. 2010. [acesso 22 jan 2011]; 10(1):88. Disponível em http://www. biomedcentral.com/1471-2318/10/88

2. Lamb M, Buchanan D, Godfrey C, Harrison M, Oakley

P. The psychosocial spiritual experience of elderly individuals recovering from stroke: a systematic review. Int J Evid Based Healthcare. 2008;6(2):173-205.

3. Puchalski C. Spirituality in the cancer trajectory. Ann Oncol. 2012;23(3):49-5.
4. Morita T, Tsunoda J, Inoue S, Chihara S. An exploratory factor analysis of existential suffering in Japanese terminally ill cancer patients. Psychooncology. 2000;9(2):164-8.

5. Narayanasamy A, Clissett P, Parumal L, Thompson D, Annasamy $S$, Edge R. Responses to the spiritual needs of older people. J Adv Nurs. 2004;48(1):6-16.

6. Pesut B, Fowler M, Taylor E, Sawatsky R. Conceptualizing spirituality and religion for health care. J Clin Nurs. 2008;17(21):2803-10.

7. Chaves E, Carvalho E, Hass V. Validação do diagnóstico de enfermagem angústia espiritual: análise por especialistas. Acta Paul Enferm. 2010; 23(2):264-70.

8. Puchalski C, Ferrell B, Virani R, Otis-Green S, Baird $\mathrm{P}$, Bull J, Chochinov $\mathrm{H}$, et al. Improving the quality of spiritual care as a dimension of palliative care: the report of the consensus conference. J Palliat Med. 2009;12(10):885-904.

9. Fowler J. Stages of Faith - The Psychology of Human Development and the Quest for Meaning. New York: HarperCollins Publishers; 1981. 332p.

10. NANDA Internacional. Diagnósticos de enfermagem: definições e classificação, 2009-2011. Porto Alegre (RS): Artmed; 2010. 452 p.

11. Cavendish R, Luise BK, Horne $K$, Bauer M, Medefindt J, Gallo MA, et al. Opportunities for enhanced spirituality relevant to well adults. Nurs Diagn. 2000;11(4):151-63. 12. Creason N. Clinical validation of nursing diagnoses. Int J Nurs Terminol Class. 2004;15(4):123-32.

13. McSherry W, Smith J. Spiritual Care - principles, values and skills. In: McSherry $W$, McSherry R, Watson R. Care in nursing. Oxford: Oxford University Press; 2012. p. 117-31.

14. Villagomeza LR. Spiritual distress in adult cancer patients - toward conceptual clarity. Holist Nurs Pract. 2005;19(6):285-94.

15. Fehring RJ. The Fehring Model. In: Carrol-Johnson $\mathrm{RM}$, Paquette $\mathrm{CJ}$, editors. Classification of nursing diagnoses: proceedings of the tenth conference of North American Nursing Diagnosis Association. Philadelphia: Lippincott; 1994. p. 55-62.

16. Gomez R, Fisher J. Domains of spiritual wellbeing and development and validation of the spiritual well-being questionnaire. Pers Indiv Diff. 2003; 35(8):1975-91.

17. Gouveia M, Marques M, Pais Ribeiro J. Versão portuguesa do questionário de bem-estar espiritual (SWBQ): análise confirmatória da sua estrutura factorial. Psicol Saúde Doenças. 2009;10(2):285-93. 
18. Chaves E, Carvalho E, Terra F, Souza L. Clinical validation of impaired spirituality in patient with chronic renal disease. Rev. Latino-Am. Enfermagem. mai-jun 2010;18(3):309-16.

19. Baldacchino D. Teaching on the spiritual dimension in care: the perceived impact on undergraduate nursing students. Nurs Educ Today. 2008;28(5):501-12.

20. Caldeira S, Narayanasamy A. Nursing educational programs about spirituality: a systematic review. Cuid'Arte Enferm. 2011;5(2):123-8.

21. Baldacchino D. Nursing competencies for spiritual care. J Clin Nurs. 2006;15(7):885-96.

22. Swinton J. Spirituality and mental health care. London: Jessica Kingsley Publishers; 2003. 221 p.

23. Grant E, Murray S, Kendall M, Boyd K, Tiller S, Ryan $D$. Spiritual issues and needs: perspectives from patients with advanced cancer and nonmalignant disease: A qualitative study. Pal Sup Care. 2004;2(4):371-8.

24. Brown A, Whitney S, Duffy J. The physician's role in the assessment and treatment of spiritual distress at the end of life. Pal Sup Care. 2006;4(1):81-6.

25. Breitbart W, Rosenfeld B, Pessin H, Kaim M, FunestiEsch J, Galietta M, et al. Depression, hopelessness, and desire for hastened death in terminally ill patients with cancer. JAMA. 2000;13(22):2907-11. 